\title{
Unsteady Natural Convection Flow through a Vertical Channel: Due to the Combined Effects of Variable Viscosity and Thermal Radiation
}

\section{Ajibade AO* and Bichi YA}

Department of Mathematics, Ahmadu Bello University, Zaria, Nigeria

\begin{abstract}
The paper investigates unsteady natural convection flow through a vertical channel due to the combined effects of variable viscosity and thermal radiation. The fluid considered in this study is an optically dense viscous incompressible fluid with all its properties assumed to be constant except for its viscosity which depends linearly with its temperature. Non-linear Rosseland approximation is used to describe the radiative heat flux in the energy equation. The mathematical model capturing the present physical situation is highly non-linear due to the presence of thermal radiation effects. The governing equations for the flow formation are solved by the Adomian decomposition method (ADM). Effects of the controlling physical parameters involved in the velocity and temperature fields are presented graphically and discussed. In the course of investigation, it was found that; the fluid velocity increases with increase in thermal radiation and viscosity variation parameters while the fluid temperature increases with increase in thermal radiation.
\end{abstract}

Keywords: Natural convection; Variable viscosity; Thermal radiation; ADM

Nomenclature and Greek symbols:

\begin{tabular}{|c|c|c|}
\hline Symbols & Interpretation & Unit \\
\hline$y^{\prime}$ & Dimensional length & $\mathrm{m}$ \\
\hline y & Dimensionless length & \\
\hline $\mathrm{t}$ & Time & s \\
\hline g & Acceleration due to gravity & $\mathrm{ms}^{-2}$ \\
\hline $\mathrm{k}$ & Thermal conductivity & $\mathrm{W} / \mathrm{mK}$ \\
\hline $\mathrm{T}$ & Dimensional temperature & $\mathrm{k}$ \\
\hline $\mathrm{h}$ & Dimensional width of the channel $\mathrm{m}$ & \\
\hline $\mathrm{H}$ & Dimensional channel width & $\mathrm{m}$ \\
\hline $\mathrm{T}_{\mathrm{w}}$ & Wall temperature & $\mathrm{K}$ \\
\hline $\mathrm{T}_{0}$ & Ambient temperature & $\mathrm{K}$ \\
\hline $\mathrm{u}, \mathrm{v}$ & Dimensional velocity & $\mathrm{ms}^{-1}$ \\
\hline$f$ & Dimensionless velocity & \\
\hline $\mathrm{v}$ & Kinematic viscosity of the fluid & $\mathrm{m}^{2} \mathrm{~s}^{-1}$ \\
\hline$\alpha$ & Thermal diffusivity & $\mathrm{m}^{2} \mathrm{~s}^{-1}$ \\
\hline$\delta$ & Absorption coefficient & \\
\hline$\beta$ & Volumetric expansion coefficient & $\mathrm{K}^{-1}$ \\
\hline$\mu$ & Variable fluid viscosity & $\mathrm{kgm}^{-1} \mathrm{~s}^{-1}$ \\
\hline$\mu_{0}$ & Dynamic viscosity of the fluid & $\mathrm{kgm}^{-1} \mathrm{~s}^{-1}$ \\
\hline $\mathrm{q}_{\mathrm{r}}$ & Radiative heat flux & $\mathrm{Wm}^{-2}$ \\
\hline$\theta$ & Temperature difference parameter & $\mathrm{K}$ \\
\hline$\theta$ & Dimensionless temperature & \\
\hline$\sigma$ & Stefan-Boltzman constant & \\
\hline a & Viscosity variation parameter & \\
\hline
\end{tabular}

$\Re$

$\mathrm{Nu}_{0} \quad$ Nusselt number at the plate $y=0$

$\mathrm{Nu}_{1} \quad$ Nusselt number at the plate $y=1$

$\tau_{0} \quad$ Skin friction at the plate $\mathrm{y}=0$

$\tau_{1} \quad$ Skin friction at the plate $y=1$.

\section{Introduction}

The study of fluid flow with variable viscosity has become of principal interest in many scientific and engineering applications, such as crude oil extraction, food processing, coating and polymer processing industries. In industrial systems, fluid can be subjected to extreme conditions such as high temperature, pressure and shear rate. External heating and high shear rate can lead to a high temperature being generated in the fluid; this leads to a significant effect on the fluid properties [1,2]. It is well known that the most sensitive fluid property to temperature rise is the viscosity and this is reported in the works of Johns and Narayanan [3], Hashemabadi et al. [4], Becker and Kingsley [5]. For many liquids, among them water, petroleum oils, glycerin, glycols, silicone fluids and some molten salts, the percent variation of absolute viscosity with temperature is much more than that of the other properties. For instance, when the temperature increases from $10^{\circ} \mathrm{C}(\tilde{\mu}=0.0133 \mathrm{~g} / \mathrm{cms})$ to $50^{\circ} \mathrm{C}(\tilde{\mu}=0.00548 \mathrm{~g} / \mathrm{cms})$ the viscosity of water decreases by $240 \%$ Carey and Mollendorf [6]. Fluids used in industries, such as polymer fluids have viscosities that vary rapidly with temperature and this may give rise to strong feedback effects [7]. The

\footnotetext{
*Corresponding author: Ajibade AO, Department of Mathematics, Ahmadu Bello University, Zaria, Nigeria, Tel: +2348068843483; E-mail: olubade2k@yahoo.com

Received May 28, 2018; Accepted July 10, 2018; Published June 18, 2018

Citation: Ajibade AO, Bichi YA (2018) Unsteady Natural Convection Flow through a Vertical Channel: Due to the Combined Effects of Variable Viscosity and Thermal Radiation. J Appl Computat Math 7: 403. doi: 10.4172/2168-9679.1000403

Copyright: (c) 2018 Ajibade AO, et al. This is an open-access article distributed under the terms of the Creative Commons Attribution License, which permits unrestricted use, distribution, and reproduction in any medium, provided the original author and source are credited.
} 
usual assumption of constant viscosity property of fluid evaluated at some reference temperature is not enough to depict the true picture in the flow characteristics in boundary layer flows. Garey et al. [8], Mehta and Sood [9] lamented that when varying viscosity property of fluid is included, the flow characteristics change substantially compared to the constant case. Kafousius et al. [10], Kafousius and Williams [11] investigated the effect of temperature-dependent viscosity on mixed convection past a vertical flat plate in the region near a leading edge and concluded that when the viscosity of the fluid is sensitive to temperature variation, the effect of temperature-dependent viscosity has to be taken into consideration; otherwise, considerable errors may occur in the characteristics of the heat transfer process. Entropy generation is a measure of destruction of the available work done by a system. When it occurs, the consequent effect is the emission of heat in the form of electromagnetic rays termed as thermal radiation. In order to minimize entropy generation, several studies were carried out to this effect; for instance, Ajibade et al. [12] studied entropy generation under the effect of suction/injection and concluded that entropy generation increases with suction on one plate and it decreases on the other plate with injection. Makinde [13] and Ibanez et al. [14] lamented that when entropy generation takes place, the quality of energy of a system decreases.

Radiation effects on the free convection flow are important in the context of space technology and processes involving high temperature. In view thereof, Makinde and Ogulu [15] analyzed the effect of thermal radiation on the heat and mass transfer flow of a variable viscosity fluid past a vertical porous plate permeated by a transverse magnetic field where they concluded that an increase in the positive value of viscosity variation parameter decreases the fluid viscosity and consequently leads to an increase in the velocity within the boundary layer. Other similar researches can be seen in Hossain et al. [16], Seddeek and Salem [17], Elbasbeshy and Bazid [18], Costa and Macedonio [19]. The expression for radiative heat flux term which is widely used in the study of heat transfer process in boundary layer flows was given by Sparrow and Cess. [20]. Despite its shortcomings of being valid for intensive absorption, that is, for optically thick boundary layer flows; several researchers have used it with success. This can be seen in Makinde et al. [21], Makinde and Ogulu [15], and Makinde and Ibrahim [22]. The latter researchers used a linearised form of temperature in the expression for radiative heat flux during their studies. However, this was condemned by Pantokratoras and Magyari [23] on the basis that; the linearized form of temperature in most boundary layer flows with thermal radiation does not portrays a real characteristics in heat emission or conduction, as such it is uncalled for any publications neither does it require any additional research efforts. They therefore proposed alternative approach in where temperature in the radiative heat flux is evaluated using normal differentiation.

In the field of science and engineering, there are few phenomena that occur linearly while most occur non-linearly. Non-linear equations are difficult to handle and some can be solved using analytical methods, semi-analytical methods or traditional numerical methods such as Homotopy analysis method (HAM), variational iteration method (VIM), Runge-Kutta method, and finite difference method. The other well-known method is the ADM proposed by Adomian [24]. Numerous researchers have used this technique in their studies, this can be viewed [25], Adesanya et al. [26], Adesanya and Makinde [27], Adesanya and Cbadeyan [28], Venkatarangan and Rajalakshmi [29] and Makinde et al. [21] a few to mention among others.

In the present article, we consider unsteady natural convection flow due to the combined effects of variable viscosity and thermal radiation which will be analysed Cherruault [30] by non-linear Rosseland diffusion approximation. Similarly, the fluid dynamic viscosity is considered to vary linearly with the fluid temperature following [6].

\section{Mathematical Formulation}

The physical problem under consideration consists of a vertical channel formed by two vertical parallel plates; stationed h distance apart. The channel is filled with viscous incompressible fluid in the presence of thermal radiation with all the fluid physical properties assumed constant except for its viscosity which is temperature dependent. Similarly, the fluid is considered optically thick where the radioactive heat flux of Roseland diffusion approximation can be utilized. The ${ }^{x}$-axis is taken along the channel in the vertically upwards direction, being the direction of the flow while the $x^{\prime}$-axis is taken normal to it. In addition, the effects of radiative heat flux in the $x^{\prime}$-direction is considered negligible compared with that in the $y^{\prime}$ -direction. At time $y=0$, both the fluid and the plates are assumed to be at rest with constant temperature $\mathrm{T}_{0}$. At time $\mathrm{t}>0$, the temperature of the plate kept at $y=0$ rise to $\mathrm{T}_{\mathrm{w}}$ while the other plate at $y=h$ is fixed and maintained at temperature $\mathrm{T}_{0}^{\mathrm{w}}$. The coordinates system and the flow configuration are shown in Figure 1 below:

Under these assumptions and on using Bouss in eqn. approximation, the appropriate governing equations are:

$$
\begin{aligned}
& \frac{\partial u}{\partial x}+\frac{\partial v}{\partial y}=0 \\
& \frac{\partial u}{\partial t}=\frac{1}{\rho} \frac{\partial}{\partial y^{\prime}}\left(\mu \frac{\partial u}{\partial y^{\prime}}\right)+g \beta\left(T-T_{0}\right) \\
& \frac{\partial T}{\partial t}=\alpha\left(\frac{\partial^{2} T}{\partial y^{\prime 2}}-\frac{1}{k} \frac{\partial q_{r}}{\partial y^{\prime}}\right)
\end{aligned}
$$

where $\mathrm{u}, \mathrm{v}$ are the velocity components in the $x^{\prime}$ and $y^{\prime}$ directions respectively, $\rho$ is the density of the ambient fluid g; the acceleration due to gravity, $\beta$ is the coefficient of thermal expansion $\mathrm{k}$; the coefficient of thermal conductivity, $\mathrm{T}$; the temperature of the fluid, $y^{\prime}$ is the ambient fluid temperature and $\mathrm{q}_{\mathrm{r}}$ is the radiative heat flux in the $y^{\prime}$ direction.

Following Carey and Mollendorf [6], the fluid dynamic viscosity is of the form:

$$
\mu=\mu_{0}\left(1-\lambda\left(\frac{T-T_{0}}{T_{w}-T_{0}}\right)\right), \lambda \in \mathfrak{R}
$$

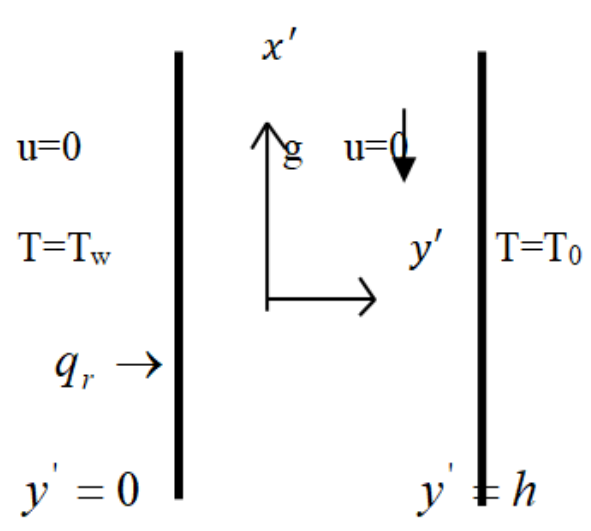

Figure 1: Schematic diagram of the problem. 
and the radiative heat flux term $\left(\mathrm{q}_{\mathrm{r}}\right)$ as given by Sparrow and Cess [20] is:

$$
q_{r}=\frac{-4 \sigma \partial T^{4}}{3 \delta \partial y}
$$

with the boundary conditions for the velocity and temperature fields as:

$$
\begin{aligned}
& \mathrm{u}=0, \mathrm{~T}=\mathrm{T}_{\mathrm{w}} \text { at } y^{\prime}=0 \\
& \mathrm{u}=0, \mathrm{~T}=\mathrm{T}_{0} \text { at } y^{\prime}=h
\end{aligned}
$$

The following dimensionless quantities are introduced:

$$
u=\frac{g \beta\left(T-T_{0}\right) \delta^{2}}{4 v}, y=\frac{y^{\prime}}{\sqrt{v t}}, \theta(y)=\frac{T-T_{0}}{T_{w}-T_{0}}, \delta=2 \sqrt{v t}
$$

using eqns. (4), (6) and (7) in eqn. (2) we have:

$$
\begin{aligned}
& f^{\prime \prime}(y)=-\frac{1}{2} y f^{\prime}(y)(1+\lambda \theta(y))+\lambda \theta^{\prime}(y) f^{\prime}(y)(1+\lambda \theta(y)) \\
& -\theta(y)(1+\lambda \theta(y)), \lambda \in \mathfrak{R}
\end{aligned}
$$

Similarly, using eqns. (5-7) in eqn. (3) give:

$$
\frac{-1}{2} y \theta^{\prime}(y)\left(T_{w}-T_{0}\right)=\left(\frac{\alpha}{v t} \theta^{\prime \prime}(y)\left(T_{w}-T_{0}\right)+\frac{\alpha}{k} \cdot \frac{\partial q_{r}}{\partial y^{\prime}}\right)
$$

The term $\frac{\partial q_{r}}{\partial y}$; containing the radioactive heat flux term $\left(\mathrm{q}_{\mathrm{r}}\right)$ in the right hand side of eqn. (9) is simplified following Pantokratoras and Magyari [23] as follows:

$$
\begin{aligned}
& \frac{\partial q_{r}}{\partial y^{\prime}}=-\frac{4 \sigma}{3 v t \delta} \frac{\partial}{\partial y}\left[\frac{\partial T^{4}}{\partial \mathrm{y}}\right]=-\frac{4 \sigma}{3 v t \delta}\left(\frac{\partial^{2}}{\partial y^{2}}\left(\left[\theta(y)\left(T_{w}-T_{0}\right)+T_{0}\right]^{4}\right)\right) \\
& =-\frac{4 \sigma}{3 v t \delta}\left(\frac{\partial}{\partial y}\left(4\left[\theta(y)\left(T_{w}-T_{0}\right)+T_{0}\right]^{3}\right) \frac{\partial}{\partial y}\left(\theta(y)\left(T_{w}-T_{0}\right)\right)\right) \\
& =-\frac{4 \sigma}{3 v t \delta}\left(12\left[\theta(y)\left(T_{w}-T_{0}\right)+T_{0}\right]^{2} \frac{\partial}{\partial y}\left(\theta(y)\left(T_{w}-T_{0}\right)\right) \frac{\partial}{\partial y}\left(\theta(y)\left(T_{w}-T_{0}\right)\right)\right)(10) \\
& -\frac{4 \sigma}{3 v t \delta}\left(4\left[\theta(y)\left(T_{w}-T_{0}\right)+T_{0}\right]^{3} \frac{\partial^{2}}{\partial y^{2}}\left(\theta(y)\left(T_{w}-T_{0}\right)\right)\right) \\
& =-\frac{4 \sigma}{3 v t \delta}\left(4\left(T_{w}-T_{0}\right)^{4}[\theta(y)+\varphi]^{3} \frac{\partial^{2}}{\partial y^{2}}(\theta(y))\right)
\end{aligned}
$$

Substituting eqn. (10) in eqn. (9) gives:

$$
\begin{aligned}
& \theta^{\prime \prime}(y)=-\frac{1}{2} y \operatorname{Pr} \theta^{\prime}(y)\left[1-\frac{4 R}{3}[\theta(y)+\varphi]^{3}\right] \\
& -4 R[\theta(y)+\varphi]^{2} \theta^{\prime}(y) \theta^{\prime}(y)\left[1-\frac{4 R}{3}[\theta(y)+\varphi]^{3}\right]
\end{aligned}
$$

Furthermore, using eqn. (6) in eqn. (4), the boundary conditions are now:

$f(0)=0, \theta(0)=1 . f(\mathrm{H})=\theta(\mathrm{H})=0$

where $R=\frac{4 \sigma\left(T_{w}-T_{0}\right)^{3}}{3 k \delta}, \varphi=\frac{T_{0}}{T_{w}-T_{0}}, \operatorname{Pr}=\frac{\alpha}{v}, H=\frac{h}{\sqrt{v t}}$

Pr represents Prandt l number which is inversely proportional to the thermal diffusivity $\alpha$ of the working fluid and $\theta$ is temperature difference parameter where $\mathrm{R}$ is the radiation parameter. The meanings of the other physical quantities involved are given in the nomenclature.

\section{Description of the ADM}

Consider the inhomogeneous nonlinear differential equation in Adomian's operator-theoretic form

\section{$\mathrm{Lu}+\mathrm{Su}+\mathrm{Nu}=\mathrm{g}$}

Where $\mathrm{u}$ is unknown function or system output, which is to be determined by a recursive relation, $\mathrm{L}$ is the invertible linear operator which is the highest order derivative $S$, is the remainder of the linear operator whose order is less than $\mathrm{L}, \mathrm{Nu}$ represents the nonlinear terms and $g$ is the source term or system input.

operating $L^{-1}$ to both sides of and using the given initial boundary conditions, we obtain

$$
u=w-L^{-1}(S u)-L^{-1}(N u)
$$

Where $\mathrm{w}$ represents the term arising from integrating the source term $g$ and the auxiliary conditions

The standard ADM defines the solution $u$ by the decomposition series

$$
u=\sum_{n=0}^{\infty} u_{n}
$$

and the nonlinear term comprises the series of the Adomian polynomials

$$
N u=\sum_{n=0}^{\infty} A_{n}
$$

where the $A_{n}$ are the Adomian polynomials generated from the relation

$$
A_{n}=\frac{1}{n !}\left[\frac{d^{n}}{d \lambda^{n}}\left[N\left(\sum_{i=0}^{\infty} \lambda_{i} u_{i}\right)\right]\right]_{\lambda=0}
$$

such that the Adomian polynomials are evaluated as

$$
\begin{aligned}
& A_{0}=f\left(w_{0}\right) \\
& A_{1}=w_{1} f^{(1)}\left(w_{0}\right) \\
& A_{2}=w_{2} f^{(1)}\left(w_{0}\right)+\frac{1}{2 !} w_{1}^{2} f^{(2)}\left(w_{0}\right) \\
& A_{3}=w_{3} f^{(1)}\left(w_{0}\right)+w_{1} w_{2} f^{(2)}\left(w_{0}\right)+\frac{1}{3 !} w_{1}^{3} f^{(3)}\left(w_{0}\right)
\end{aligned}
$$

The solution components $\mathrm{u}_{0}, \mathrm{u}_{1}, \mathrm{u}_{2}, \ldots \ldots$ are determined recursively as follows

$$
\begin{aligned}
& \mathrm{u}_{0}=\mathrm{w} \\
& u_{k+1}=-L^{-1}\left(S u_{k}\right)-L^{-1}\left(N u_{k}\right), k \geq 0
\end{aligned}
$$

Where $\mathrm{w}_{0}$ is referred to as the zeroth-order component.

\section{Adomian decomposition solution of the problem}

Eqns. (10) and (11) under the boundary conditions (12) are solved as follows:

Denote by $f^{\prime \prime}=\frac{d^{2} f}{d y^{2}}, \theta^{\prime \prime}=\frac{d^{2} \theta}{d y^{2}}$ and let $L(y)=\frac{d^{2} f}{d y^{2}}$, so that $L f(y)=f^{\prime \prime}(y)$

and $L \theta(y)=\theta^{\prime \prime}(y)$

then $L^{-1}=\int_{0}^{y} \int_{0}^{y}() d Y d$.

eqn. (10) and eqn. (11) can now be written as: 


$$
\begin{aligned}
L f(y) & =-\frac{1}{2} y f^{\prime}(y)(1+\lambda \theta(y))+\lambda \theta^{\prime}(y) f^{\prime}(y)(1+\lambda \theta(y)) \\
-\theta(y)(1+\lambda \theta(y)), \quad \lambda \in \Re & \\
L \theta(y) & =-\frac{1}{2} y \operatorname{Pr} \theta^{\prime}(y)\left[1-\frac{4 R}{3}[\theta(y)+\varphi]^{3}\right] \\
& -4 R[\theta(y)+\varphi]^{2} \theta^{\prime}(y) \theta^{\prime}(y)\left[1-\frac{4 R}{3}[\theta(y)+\varphi]^{3}\right]
\end{aligned}
$$

Operating on both sides of eqns. (24) and (25), we obtain:

$$
L^{-1} L f(y)=--L^{-1}\left(y f^{\prime}(y)(1+\lambda \theta(y))\right)+\lambda L^{-1}\left(\theta^{\prime}(y) f^{\prime}(y)(1+\lambda \theta(y))\right)
$$$$
-L(\theta(y)(1+\lambda \theta(y)))
$$

$$
\begin{aligned}
& L^{-1} L \theta(y)=-\frac{1}{2} \operatorname{Pr} L^{-1}\left(y \theta^{\prime}(y)\left[1-\frac{4 R}{3}[\theta(y)+\varphi]^{3}\right]\right) \\
& -4 R L^{-1}\left([\theta(y)+\varphi]^{2} \theta^{\prime}(y) \theta^{\prime}(y)\left[1-\frac{4 R}{3}[\theta(y)+\varphi]^{3}\right]\right)
\end{aligned}
$$

By ADM:

$$
\begin{aligned}
& L^{-1} L f(y)=f(y)-f(0)-y f^{\prime}(0) \\
& L^{-1} L \theta(y)=\theta(y)-\theta(0)-y \theta^{\prime}(0)
\end{aligned}
$$

Using eqns. (10), (28) and (29) in eqns. (26) and (27), respectively we have:

$$
\begin{aligned}
& -L^{-1}(\theta(y)(1+\lambda \theta(y))) \\
& \theta(y)=1+y B-\frac{1}{2} \operatorname{Pr} L^{-1}\left(y \theta^{\prime}(y)\left[1-\frac{4 R}{3}[\theta(y)+\varphi]^{3}\right]\right) \\
& \quad-4 R L^{-1}\left([\theta(y)+\varphi]^{2} \theta^{\prime}(y) \theta^{\prime}(y)\left[1-\frac{4 R}{3}[\theta(y)+\varphi]^{3}\right]\right)
\end{aligned}
$$

According to the standard $\mathrm{ADM}, f(\mathrm{y})$ and $\theta(\mathrm{y})$ may be expressed as:

$$
f(y)=\sum_{n=0}^{\infty} f_{n}(y), \theta(y)=\sum_{n=0}^{\infty} \theta_{n}(y)
$$

Putting eqn. (32) in eqns. (30) and (31) respectively, we have:

$$
\begin{aligned}
& \sum_{n=0}^{\infty} f_{n}(y)=y A-\frac{1}{2} L^{-1}\left(y \frac{d}{d y}\left(\sum_{n=0}^{\infty} f_{n}(y)\right)\left(1+\lambda \sum_{n=0}^{\infty} \theta_{n}(y)\right)\right) \\
& \quad+\lambda L^{-1}\left(\frac{d}{d y}\left(\sum_{n=0}^{\infty} \theta_{n}(y)\right) \frac{d}{d y}\left(\sum_{n=0}^{\infty} f_{n}(y)\right)\left(1+\lambda \sum_{n=0}^{\infty} \theta_{n}(y)\right)\right) \\
& -L^{-1}\left(\sum_{n=0}^{\infty} \theta_{n}(y)\left(1+\lambda \sum_{n=0}^{\infty} \theta_{n}(y)\right)\right) \\
& \sum_{n=0}^{\infty} \theta_{n}(y)=1+y B-\frac{1}{2} \operatorname{Pr} L^{-1}\left(y \frac{d}{d y}\left(\sum_{n=0}^{\infty} \theta_{n}(y)\right)\left[1-\frac{4 R}{3}\left[\sum_{n=0}^{\infty} \theta_{n}(y)+\varphi\right]^{3}\right]\right) \\
& -4 R L^{-1}\left(\left[\sum_{n=0}^{\infty} \theta_{n}(y)+\varphi\right]^{2} \frac{d}{d y}\left(\sum_{n=0}^{\infty} \theta_{n}(y)\right) \frac{d}{d y}\left(\sum_{n=0}^{\infty} \theta_{n}(y)\right)\left[1-\frac{4 R}{3}\left[\sum_{n=0}^{\infty} \theta_{n}(y)+\varphi\right]^{3}\right]\right)
\end{aligned}
$$

Setting $f_{0}(\mathrm{y})=$ Ay and $\theta_{0}(\mathrm{y})=1+$ By then $f_{\mathrm{j}+1}(\mathrm{y})$ and $\theta_{\mathrm{j}+1}(\mathrm{y})$ for $\mathrm{j} \geq 0$ are determined using the recursive relations:

$$
\begin{aligned}
& f_{j+1}(y)=\frac{1}{2} L^{-1}\left(y \frac{d}{d y}\left(f_{j}(y)\right)\left(1+\lambda \theta_{j}(y)\right)\right)+\lambda L^{-1}\left(\frac{d}{d y}\left(\theta_{j}(y)\right) \frac{d}{d y}\left(\theta_{j}(y)\right)\left(1+\lambda \theta_{j}(y)\right)\right) \\
& -L^{-1}\left(\theta_{j}(y)\left(1+\lambda \theta_{j}(y)\right)\right), j \geq 0
\end{aligned}
$$

and

$$
\begin{aligned}
& \theta_{j+1}(y)=-\frac{1}{2} \operatorname{Pr} L^{-1}\left(y \frac{d}{d y}\left(\theta_{j}(y)\right)\left[1-\frac{4 R}{3}\left[\theta_{j}(y)+\varphi\right]^{3}\right]\right) \\
& -4 R L^{-1}\left(\left[\theta_{j}(y)+\varphi\right]^{2} \frac{d}{d y}\left(\theta_{j}(y)\right) \frac{d}{d y}\left(\theta_{j}(y)\right)\left[1-\frac{4 R}{3}\left[\theta_{j}(y)+\varphi\right]^{3}\right]\right), j \geq 0
\end{aligned}
$$

\section{Convergence analysis}

Convergence of ADM solution has been given in Adomian [24] and Charruault [30]. Despite this, to verify the convergence of our ADM solution in the present problem, we deploy the method of ratio test for convergence. Using computer simulation, the following ADM series of eqn. ( 35 and 36 ) at $\mathrm{y}=0.5, \mathrm{R}=0.1, \theta=0.1, \lambda=0.1, \operatorname{Pr}=0.71$ are obtained as follows:

$\theta_{0}=0.4729720015, \theta_{2}=-0.00008134291586, \theta_{3}=0.0000008523379614$ $, \theta_{4}=-4.4144946266 \times 10^{-10}, f_{0}=0.06376280558, f_{1}=-0.004159525801, f_{2}=0.0$ $0009144558899, f_{3}=-0.00000159539894, f_{4}=2.202779961 \times 10^{-8}$.

On the application of ratio test, it can be seen that; all the terms in eqn. (37) satisfied the ratio test formula for convergence i.e. $\lim _{j \rightarrow \infty}\left|\frac{f_{j+1}}{f_{j}}\right|<1$. Hence, the ADM solution in the present problem converges.

\section{Termination criterion}

For an infinite series solution to be meaningful, the solution needs to be terminated at a point such that any additional term contributes insignificantly to the final solution. Our solution is thus truncated whenever $\left|f_{\mathrm{j}}\right|<\delta$ and $\left|\theta_{\mathrm{i}}\right|<\xi$. For the present problem, we have chosen $\delta=1.6^{\star} 10^{-7}$ and $\xi=8.5^{\star} 10^{-7}$. Based on this assumption, the approximate solution is truncated after the $3^{\text {rd }}$ term. Due to the cumbersome of the computed ADM series solution obtained via computer coded simulation; only numerical and graphical results are presented for the purpose of discussion.

Nusselt numbers on the channel walls are obtained respectively via:

$$
N u_{0}=-\left.\frac{d \theta}{d y}\right|_{y=0} \text { and } N u_{1}=\left.\frac{d \theta}{d y}\right|_{y=1}
$$

and the skin friction on the walls are calculated using:

$$
\tau_{0}=\left.\frac{d f}{d y}\right|_{y=0} \text { and } \tau_{1}=-\left.\frac{d f}{d y}\right|_{y=1} .
$$

\section{Validation of the result}

Eqns. (8) and (11) representing the flow governing equations are highly non-linear differential equations. In order to validate our result, we compare the ADM solution of these equations with that achieved via series solution of the same problem in the absence of thermal radiation and viscosity variation parameter, that is setting $\lambda=0$ in eqn. (8) and $\mathrm{R}=0$ in eqn. (11) we obtain the followings differential equations:

$$
\begin{aligned}
& \theta^{\prime \prime}(y)+\frac{1}{2} \operatorname{Pr} y \theta^{\prime}(y)=0 \\
& f^{\prime \prime}(y)+\frac{1}{2} f^{\prime}(y)+\theta(y)=0
\end{aligned}
$$

Applying series method of solution to solve eqn. (40) is as follows:

Let $\theta(y)=\sum_{n=0}^{\infty} a_{n} y^{n}$ so that $\theta^{\prime}(y)=\sum_{n=0}^{\infty} n a_{n} y^{n-1}$ and $\theta^{\prime \prime}(y)=\sum_{n=0}^{\infty} n(n-1) a_{n} y^{n-2}$

Substituting eqn. (42) in eqn. (40) together with the boundary conditions (12) in eqn. (12) and simplifying, we obtained the following series solution: 


$$
\begin{aligned}
\theta:=1+\frac{13440 y}{5 \operatorname{Pr}^{3}-84 \operatorname{Pr}^{2}+1120 \operatorname{Pr}-13440}-\frac{1120 \operatorname{Pr} y^{3}}{5 \operatorname{Pr}^{3}-84 \operatorname{Pr}^{2}+1120 \operatorname{Pr}-13440} \\
+\frac{84 \operatorname{Pr}^{2} y^{5}}{5 \operatorname{Pr}^{3}-84 \operatorname{Pr}^{2}+1120 \operatorname{Pr}-13440}-\frac{5 \operatorname{Pr}^{3} y^{7}}{5 \operatorname{Pr}^{3}-84 \operatorname{Pr}^{2}+1120 \operatorname{Pr}-13440}
\end{aligned}
$$

Similarly; applying series method to solve eqn. (41) is as follows:

$$
\text { Let } f(y)=\sum_{n=0}^{\infty} b_{n} y^{n} \text { so that } f^{\prime \prime}(y)=\sum_{n=0}^{\infty} n(n-1) b_{n} y^{n-2} \text { and } f^{\prime \prime}(y)=\sum_{n=0}^{\infty} n(n-1) b_{n} y^{n-2}
$$

Substituting eqn. (44) together with the boundary conditions (12) and eqn. (43) in eqn. (41) we obtained the following series solution:

$$
\begin{aligned}
& f(y)=\left(\frac{1}{48}-\frac{280}{3} \frac{\operatorname{Pr}}{5 \operatorname{Pr}^{3}-84 \mathrm{Pr}^{2}+1120 \operatorname{Pr}-13440}\right) y^{4}+\left(\begin{array}{l}
-\frac{1}{5 \cdot \operatorname{Pr}^{3}-84 \cdot \mathrm{Pr}^{2}+1120 \cdot \operatorname{Pr}-13440}\left(3.03030303010^{-12}\right. \\
\left(7.18750000010^{10} \mathrm{Pr}^{3}-1.20750000010^{12} \operatorname{Pr}^{2}\right. \\
\left.+1.89000000010^{13} \mathrm{Pr}-1.26000000010^{14}\right)
\end{array}\right) \\
& \left.-\frac{2240}{5 \mathrm{Pr}^{3}-84 \mathrm{Pr}^{2}+1120 \operatorname{Pr}-13440}\right) y^{3}-0.5 y^{2}+\frac{1}{5 \cdot \mathrm{Pr}^{3}-84 \cdot \mathrm{Pr}^{2}+1120 \cdot \operatorname{Pr}-13440}\left(3 . 6 3 6 3 6 3 6 3 6 1 0 ^ { - 1 1 } \left(7.187500000010^{10}\right.\right. \\
& \operatorname{Pr}^{3}-1.20750000010^{12} \mathrm{Pr}^{2} \\
& \left.+1.890000000010^{13} \mathrm{Pr}-1.2600000010^{14}\right) y
\end{aligned}
$$

\section{Results and Discussions}

Using computer algebra software package, eqns. (35) and (36) are simulated and the results are presented graphically as velocity and temperature profiles in order to examine the effects of the physical parameters involved in the problem. For the purpose of discussion, the

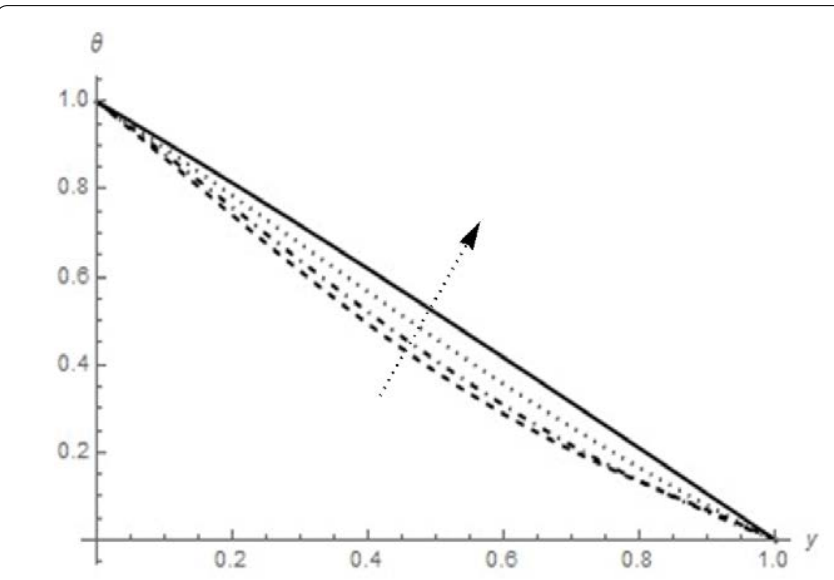

Figure 2: Temperature profile for different $\operatorname{Pr}(R=0.1, \lambda=0.1, \operatorname{Pr}=\{7,4,0.710 .015\})$.

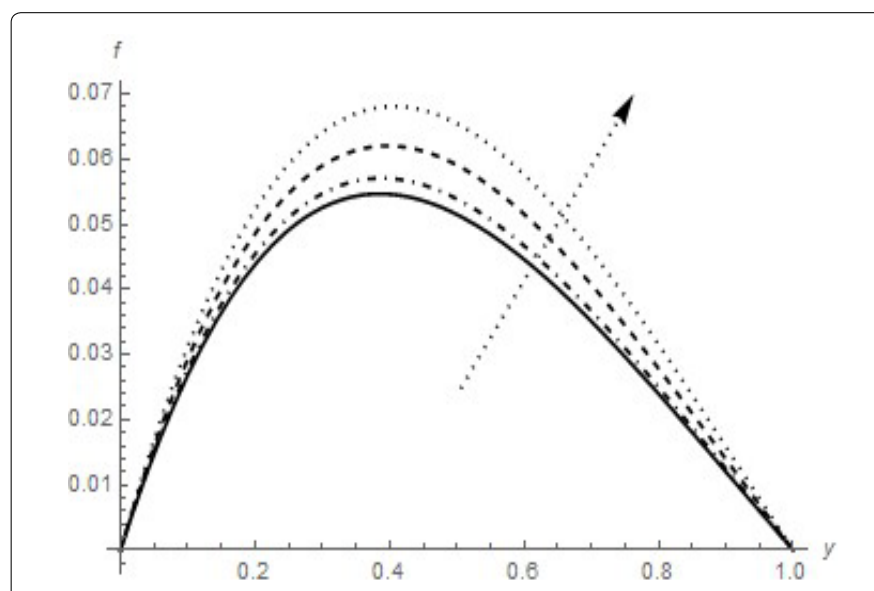

Figure 3: Velocity profile for different $\operatorname{Pr} \theta: 0.1, R=0.1, \lambda=0.1, \operatorname{Pr}=\{7,4,0.71,0.015\}$. value of Pr has been chosen as $0.015,0.71,1.0$ and 4.0 which correspond to important fluids; mercury, air, electrolyte solution and refrigerant respectively. The values of radiation parameter $(\mathrm{R})$, temperature difference parameter $\theta$ and viscosity parameter $\lambda$ are chosen between 0.1 and 0.4

Figure 2 demonstrates the effects of varying Prandtl number (Pr) on the fluid temperature. It is noticed that the temperature of the fluid within the channel decreases as Pr increases. This due to the fact that, fluid with higher Pr possesses lower thermal conductivity and as such heat diffuse slower than in fluid with lower Pr. The consequent effect of the decrease in the heat generation within the channel has gone further to affect the fluid velocity; this can be seen in Figure 3. This figure shows that, when Pr increases, it strengthen cohesive force between the fluid molecules and as such fluid with higher Pr flow slowly than fluid with lower Pr. The effect of thermal radiation (R) is observed in Figure 4, this figure shows that the fluid velocity increases with an increase in $\mathrm{R}$. This is owing to the fact that; when $\mathrm{R}$ increases, the thermal conductivity of the fluid within the channel is also increased. The transitive effect of this is reflected in Figure 5, where the fluid velocity is also seen to increase with increasing $\mathrm{R}$. This is owing to the fact that, the buoyancy force of the fluid is increased there by making flow fast. Similarly, the effect of temperature difference parameter $(\phi)$ is illustrated in Figure

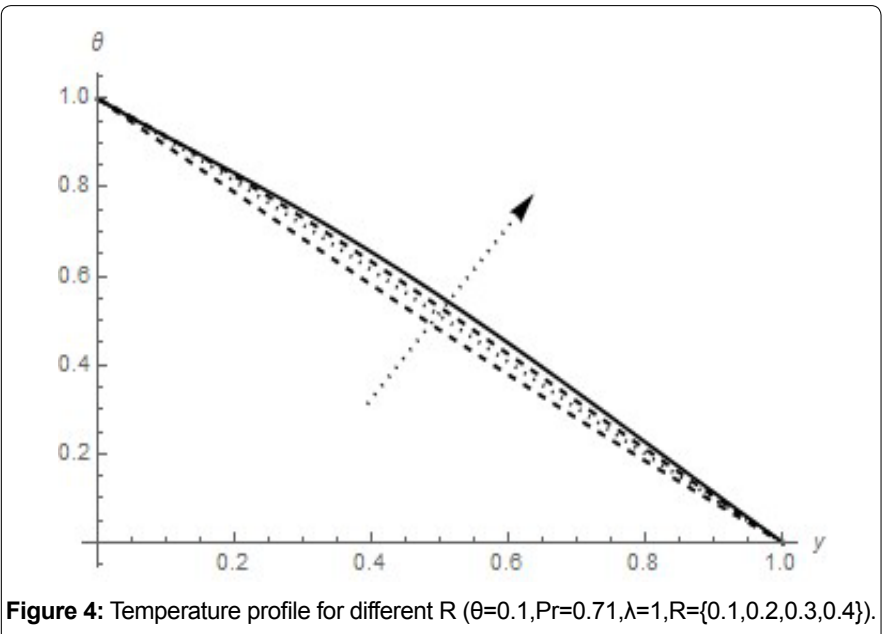

Figure 4: Temperature profile for different $R(\theta=0.1, \operatorname{Pr}=0.71, \lambda=1, R=\{0.1,0.2,0.3,0.4\})$.

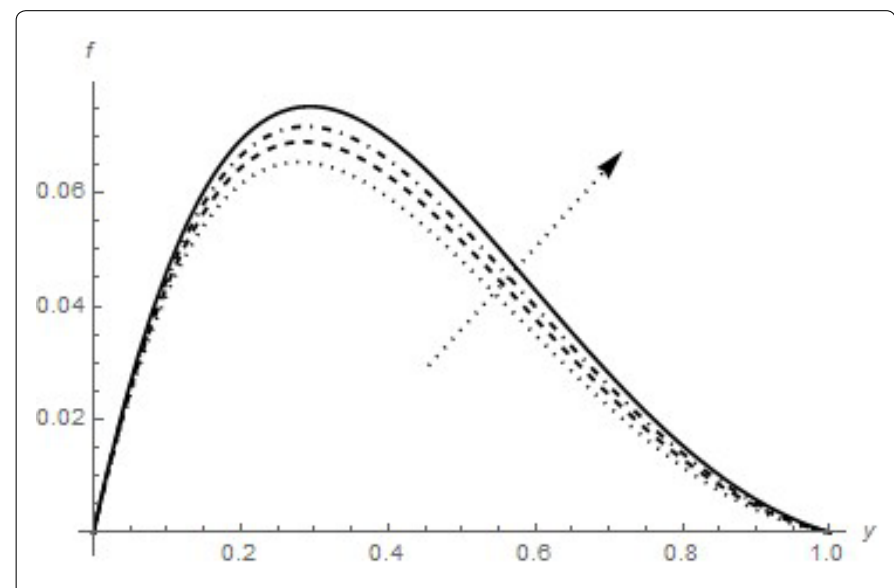

Figure 5: Velocity profile for different $R(\theta=0.1, \operatorname{Pr}=0.71, \lambda=0.1, R=\{0.1,0.2,0.3,0.4\})$ 


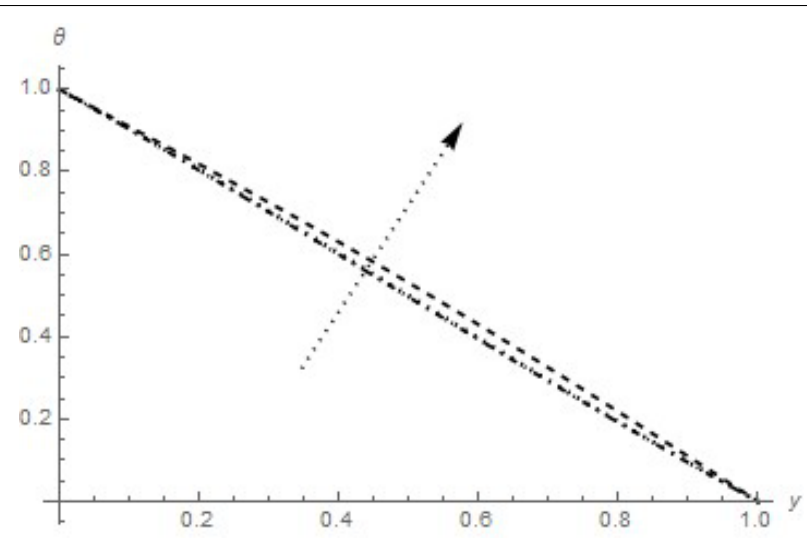

Figure 6: Temperature profile for different $\theta(\mathrm{R}=0.1, \operatorname{Pr}=0.71, \lambda=0.1$ $, \theta=\{0.1,0.2,0.3,0.4\})$.
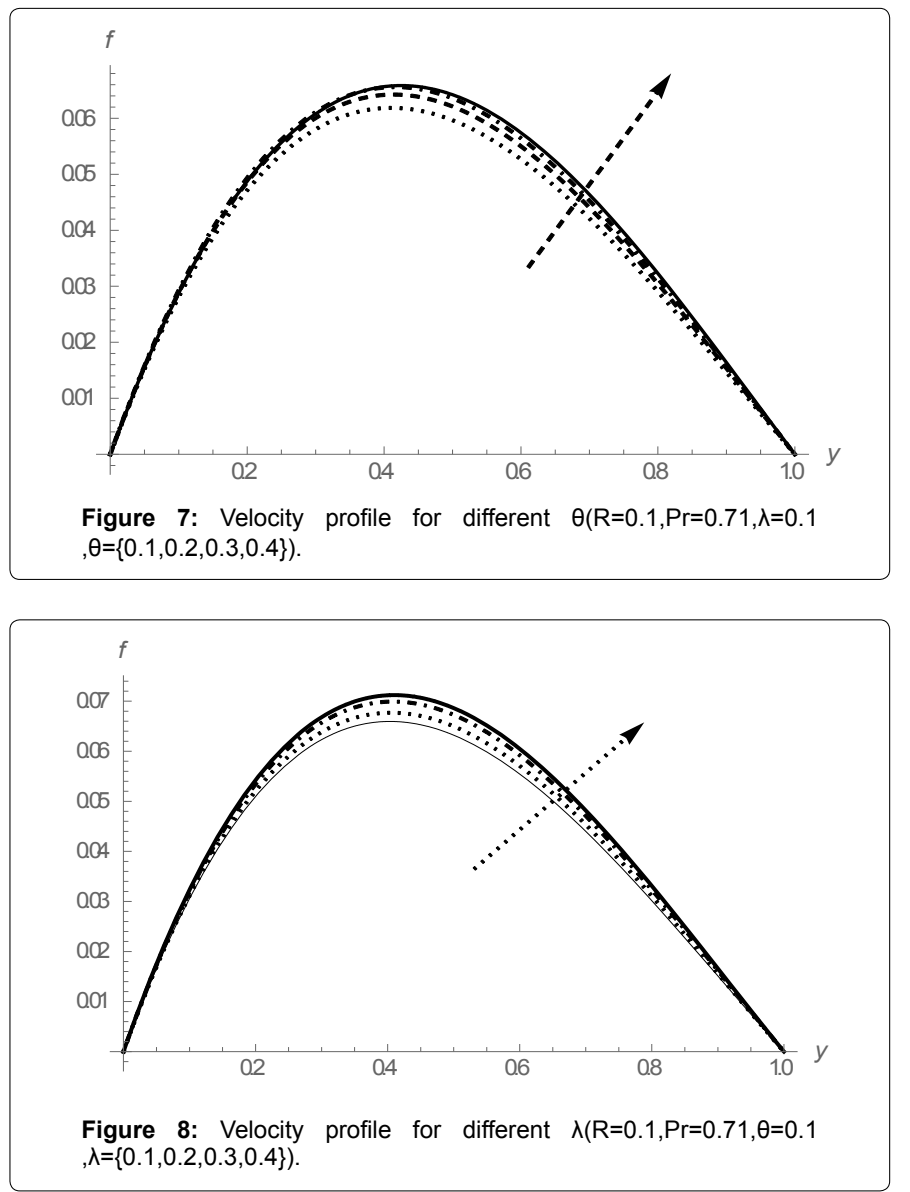

6 where the fluid temperature is observed to increases with increase in $\phi$. Thus, when $\left(T_{w}-T_{0}\right)$ is decreased, the consequent result is a corresponding increase in $\phi$. In the same vein, Figure 7 shows the velocity profile under the effect of $\phi$. It is viewed from the figure that, the velocity increases with an increase in $\phi$. Increasing the value of $\phi$ loosens the cohesive force between the fluid molecules and this resulted into speedy flow of the fluid. Finally, the effect of viscosity parameter $(\lambda)$ is revealed in Figure 8. It portrays that, the fluid velocity increases with increase in $\lambda$. The increase in velocity is caused by the decrease in viscosity of the fluid when $\lambda$ increases.
Table 1 shows comparison between ADM and series solution of the present problem when $\mathrm{R}=0$ and $\lambda=0$. The table displayed that, the solution of the problem under study by ADM coincides with that of the same

problem obtained using series solution method all in the absence of thermal radiation and viscosity variation parameter.

The effects of Prandtl numbers on the Nusselt number are shown in Table 2. It is observed that; the Nusselt number on the channel wall stationed at $y=0$ increases with increase in $\operatorname{Pr}$ while it decreases with increase in Pr on the wall kept at $y=1$. Furthermore, the Nusselt number on the wall fixed at $y=0$ is observed to decrease with increase in $\mathrm{R}$ whereas it is found to increase with increase in $\mathrm{R}$ on the wall at $y=1$; all at maintained value of Pr. Once more, the Nusselt number on the wall at $y=0$ is noticed to decrease with increase in $\theta$ but it is seen to increase with increase in $\theta$ on the wall at $y=1$; all at fixed value of $\operatorname{Pr}$.

The Table 3 above shows the effects of viscosity variation parameter $(\lambda)$ on the skin friction. It can be viewed that; the skin friction on the channel walls decreases with increase in $\lambda$. Moreover, the skin friction on the walls is found to increase with increase in $\mathrm{R}$ and $\theta$; all for a fixed value of $\lambda$.

\section{Conclusion}

This article studied unsteady natural convection flow with thermal radiation in a vertical channel by invoking non-linear Rosseland diffusion approximation in the energy equation. The model representing the present physical situation is highly non linear due to the presence of thermal radiation effect. A semi-analytical method (ADM) together with computer algebra package for simulation has been deployed for the solution of the flow equations. The impacts of the essential controlling physical parameters involved in the problem are both graphically and computationally examined. Furthermore; comparison between the ADM and series solutions of the studied problem; in the absence of thermal radiation has been carried out in Table 1 to validate our result. Nusselt numbers and skin frictions on the bounded channel walls has also been presented in Tables 2 and 3 and discussed. The following results were deduced from the study:

i. The fluid velocity and its temperature within the channel were found to decrease with increase in Prandtl numbers.

ii. The temperature of the fluid and its velocity in the flow model were both seen to decrease with increase in thermal radiation and temperature difference parameter respectively.

iii. Increase in viscosity variation parameter was noticed to results into corresponding increase in the fluid velocity within the channel.

iv. Numerical comparison between the ADM solution and the series solution of the studied problem when both thermal radiation and viscosity variation parameter were relaxed has been conducted and presented in Table 1 . The result shows an excellent agreement between the two methods.

v. It is worthy to mention here that; when viscosity of any working fluid is sensitive to temperature change, the effects of variable viscosity has to be taken into account otherwise considerable errors may occur.

vi. This study is hoped to serve as a compliment to previous ones and also be an avenue for further researches. 
Citation: Ajibade AO, Bichi YA (2018) Unsteady Natural Convection Flow through a Vertical Channel: Due to the Combined Effects of Variable Viscosity and Thermal Radiation. J Appl Computat Math 7: 403. doi: 10.4172/2168-9679.1000403

Page 7 of 8

\begin{tabular}{|c|c|c|c|c|}
\hline$y$ & $\begin{array}{c}\text { ADM Solution } \\
\operatorname{Pr}=0.71, R=0, \theta(y)\end{array}$ & $\begin{array}{c}\text { Series Solution } \\
\text { Pr=0.71, } R=0 \\
\theta(y)\end{array}$ & $\begin{array}{c}\text { ADM Solution } \\
\text { Pr=0.71, R=0, } \Lambda= \\
0 f(y)\end{array}$ & $\begin{array}{c}\text { Series Solution } \\
\text { Pr=0.71, } R=0, \lambda=0 \\
f(y)\end{array}$ \\
\hline 0.1 & 0.8941137051 & 0.8941137052 & 0.0276449020 & 0.02759155975 \\
\hline 0.2 & 0.7886025293 & 0.7886025294 & 0.0462402538 & 0.04611689205 \\
\hline 0.3 & 0.6838376099 & 0.6838376100 & 0.0568085498 & 0.05656709524 \\
\hline 0.4 & 0.5801821910 & 0.5801821912 & 0.0604331342 & 0.05999580516 \\
\hline 0.5 & 0.4779878556 & 0.4779878559 & 0.0582388612 & 0.0575191945 \\
\hline 0.6 & 0.3775909696 & 0.3775909699 & 0.0513730368 & 0.0503159738 \\
\hline 0.7 & 0.2793094114 & 0.2793094117 & 0.0409867369 & 0.0396273906 \\
\hline 0.8 & 0.1834396557 & 0.1834396559 & 0.0282165962 & 0.0267572296 \\
\hline 0.9 & 0.0902542855 & 0.0902542856 & 0.0141671603 & 0.0140718130 \\
\hline 1.0 & $6.4000 \times 10^{-10}$ & $5.59448 \times 10^{-17}$ & 0.000106104 & $3.00 \times 10^{-10}$ \\
\hline
\end{tabular}

Table 1: Computations showing comparison between ADM and series solution.

\begin{tabular}{|c|c|c|c|c|c|c|}
\hline \multirow{2}{*}{$\operatorname{Pr}$} & \multicolumn{2}{|c|}{$\mathrm{R}=0.1, \quad \theta=0.21$} & \multicolumn{2}{|c|}{$R=0.2, \theta=0.21$} & \multicolumn{2}{|c|}{$R=0.2,0, \theta=0.5$} \\
\hline & $\mathrm{Nu}_{0}$ & $\mathrm{Nu}_{1}$ & $\mathrm{Nu}_{0}$ & $\mathrm{Nu}_{1}$ & $\mathrm{Nu}_{0}$ & $\mathrm{Nu}_{1}$ \\
\hline 0.015 & 0.883279 & 1.06001 & 0.825257 & 1.107800 & 0.824158 & 1.171530 \\
\hline 0.71 & 0.924742 & 0.956932 & 0.856568 & 1.017510 & 0.850279 & 1.097740 \\
\hline 1.00 & 1.004730 & 0.86902 & 0.872138 & 0.986143 & 0.837041 & 0.921653 \\
\hline 4.00 & 1.197150 & 0.278266 & 1.054080 & 0.448140 & 0.984510 & 0.647312 \\
\hline
\end{tabular}

Table 2: Numerical values for the rate of heat transfer on the channel walls.

\begin{tabular}{|c|c|c|c|c|c|c|}
\hline & \multicolumn{2}{|c|}{$\mathrm{R}=0.1, \theta=0.21, \mathrm{Pr}=0.71$} & \multicolumn{2}{|c|}{$\mathrm{R}=0.2, \theta=0.21, \mathrm{Pr}=0.71$} & \multicolumn{2}{|c|}{$R=0.2, \theta=0.5, \operatorname{Pr}=0.71$} \\
\hline & $\mathbf{T}_{0}$ & $T_{1}$ & $\mathbf{T}_{0}$ & $\mathrm{~T}_{1}$ & $\mathbf{T}_{0}$ & $\mathrm{~T}_{1}$ \\
\hline 0.1 & 0.671850 & 0.327637 & 0.687608 & 0.338249 & 0.699419 & 0.348278 \\
\hline 0.2 & 0.636111 & 0.275282 & 0.655659 & 0.284512 & 0.670454 & 0.293241 \\
\hline 0.4 & 0.541832 & 0.153239 & 0.570121 & 0.161570 & 0.591764 & 0.167642 \\
\hline 0.6 & 0.416437 & 0.013986 & 0.455034 & 0.017246 & 0.484687 & 0.020591 \\
\hline
\end{tabular}

Table 3: Numerical values of skin friction on the walls.

\section{References}

1. Macosko CW, Larson RG (1994) Rheology: principles, measurements, and applications.

2. Tasnim SH, Mahmud S (2002) Entropy generation in a vertical concentric channel with temperature dependent viscosity. International Communications in Heat and Mass Transfer 29: 907-918.

3. Johns LE, Narayanan R (1997) Frictional heating in plane Couette flow. In: Proceedings of the Royal Society of London A. Mathematical, Physical and Engineering Sciences 453: 1653-1670.

4. Hashemabadi SH, Etemad SG, Thibault J (2004) Forced convection hea transfer of Couette-Poiseuille flow of nonlinear viscoelastic fluids between parallel plates. Int J Heat Mass Transf 47: 3985-3991.

5. Becker LE, McKinley GH (2000) The stability of viscoelastic creeping plane shear flows with viscous heating. J Nonnewton Fluid Mech 92: 109-133.

6. Carey VP, Mollendorf JC (1978) Natural convection in liquids with temperaturedependent viscosity. In Proceedings of the Sixth International Heat Transfer Conference, Toronto 2: 211-217.

7. Şahin AZ (1999) The effect of variable viscosity on the entropy generation and pumping power in a laminar fluid flow through a duct subjected to constant heat flux. Heat and Mass Transfer 35: 499-506.

8. Gary J, Kassoy DR, Tadjeran H, Zebib A (1982) The effects of significan viscosity variation on convective heat transport in water-saturated porous media. J Fluid Mech 117: 233-249.

9. Mehta KN, Sood S (1992) Transient free convection flow with temperature dependent viscosity in a fluid saturated porous medium. Int J Eng Sci 30: 10831087.

10. Kafoussias NG, Rees DAS, Daskalakis JE (1998) Numerical study of the combined free-forced convective laminar boundary layer flow past a vertical isothermal flat plate with temperature-dependent viscosity. Acta Mechanica 127: 39-50.
11. Kafoussias NG, Williams EW (1995) The effect of temperature-dependen viscosity on free-forced convective laminar boundary layer flow past a vertical isothermal flat plate. Acta Mechanica 110: 123-137.

12. Ajibade AO, Jha BK, Omame A (2011) Entropy generation under the effect of suction/injection. Appl Math Model 35: 4630-4646.

13. Makinde OD (2008) Entropy-generation analysis for variable-viscosity channe flow with non-uniform wall temperature. Applied Energy 85: 384-393.

14. Ibáñez G, Cuevas S, de Haro ML (2003) Minimization of entropy generation by asymmetric convective cooling. Int J Heat Mass Transf 46: 1321-1328.

15. Makinde OD, Ogulu A (2008) The effect of thermal radiation on the heat and mass transfer flow of a variable viscosity fluid past a vertical porous plate permeated by a transverse magnetic field. Chemical Engineering Communications 195: 1575-1584.

16. Hossain MA, Khanafer K, Vafai K (2001) The effect of radiation on free convection flow of fluid with variable viscosity from a porous vertical plate. Int $J$ Therm Sci 40: 115-124.

17. Seddeek MA, Salem AM (2006) Further results on the variable viscosity with magnetic field on flow and heat transfer to a continuous moving flat plate. Physics Letters A 353: 337-340.

18. Elbashbeshy EMA, Bazid MAA (2000) The effect of temperature-dependent viscosity on heat transfer over a continuous moving surface. Journal of Physics D: Applied Physics 33: 2716

19. Costa A, Macedonio G (2003) Viscous heating in fluids with temperaturedependent viscosity: implications for magma flows.

20. Sparrow EM, Cess RD (1978) Radiation heat transfer. Series in thermal and fluids engineering.

21. Makinde OD, Olajuwon BI, Gbolagade AW (2007) Adomian decomposition approach to a boundary layer flow with thermal radiation past a moving vertical porous plate. Int J Appl Math Mech 3: 62-70. 
Citation: Ajibade AO, Bichi YA (2018) Unsteady Natural Convection Flow through a Vertical Channel: Due to the Combined Effects of Variable Viscosity and Thermal Radiation. J Appl Computat Math 7: 403. doi: 10.4172/2168-9679.1000403

Page 8 of 8

22. Ibrahim SY, Makinde OD (2011) Radiation effect on chemically reacting magnetohydrodynamics (MHD) boundary layer flow of heat and mass transfer through a porous vertical flat plate. Int J Phys Sci 6: 1508-1516.

23. Magyari E, Pantokratoras A (2011) Note on the effect of thermal radiation in the linearized Rosseland approximation on the heat transfer characteristics of various boundary layer flows. International Communications in Heat and Mass Transfer 38: 554-556.

24. Adomian G (1994) Solving frontier problems of physics: The decomposition method Kluwer.

25. Fathizadeh M, Aroujalian A (2012) Study of Boundary Layer Convective Heat Transfer with Low Pressure Gradient Over a Flat Plate Via He's Homotopy Perturbation Method.

26. Adesanya SO, Oluwadare EO, Falade JA, Makinde OD (2015) Hydromagnetic natural convection flow between vertical parallel plates with time-periodic boundary conditions. J Magn Magn Mater 396: 295-303.

27. Adesanya SO, Makinde OD (2015) Thermodynamic analysis for a third grade fluid through a vertical channel with internal heat generation. Journal of Hydrodynamics, 27(2), 264-272.

28. Adesanya SO, Gbadeyan JA (2011) Adomian decomposition approach to steady visco elastic fluid flow with slip through a planer channel. Int J Nonlinear Sci 11: 86-94.

29. Venkatarangan SN, Rajalakshmi K (1995) Modification of Adomian's decomposition method to solve equations containing radicals. Comput Math Appl 29: 75-80.

30. Cherruault $Y$ (1990) Convergence of Adomian's method. Mathematical and Computer Modelling: An International Journal 14: 83-86. 